LEONARDO NIRO

\title{
Social Evolution, Progress and Teleology in Spencer's Synthetic Philosophy and Freudian Psychoanalysis
}

\section{Introduction}

"It's an odd thing that one half of mankind is looking for salvation in the future and the other half in the past," ingeniously noted the anti-hero Ulrich, in Musil's classic novel of fin-de siècle Vienna The Men Without Qualities (1953, p. 323). Indeed, as Nisbet (1994) argued in his extensive survey of ideas of progress across history, "No single idea has been more important than, perhaps as important as, the idea of progress in Western civilization for nearly three thousand years" (p. 5). From Plato's early thesis elaborated in The Laws (346 B.C.) that human society evolved through time to more complex forms, to Pinker's controversial Better Angels of our Nature (2011), which sought to demonstrate that institutionalized government brought about a long 'pacification process' of reduction of violence, authors have repeatedly speculated on whether we are approaching or departing from a utopian "Golden Age."

Such wide speculations about the past and future of humankind take particular shapes that are informed by their social contexts. From the end of the eighteenth, and increasingly from the mid-nineteenth century, ideas about progress became intertwined with the many doctrines on evolution available at the time. This is the case of social evolutionism's most prominent author, Herbert Spencer, but also of Sigmund Freud. By arguing that Freud was a social evolutionist in a similar vein as Spencer, this paper attempts to bridge a gap in both the Freudian and sociological scholarship that seems to have disregarded this aspect of his work. Though substantial attention has been 
given to the impact of evolutionary theories in psychoanalysis, especially since Sulloway's book (1979), these have generally focused on Freud's individual psychology, overlooking its impact in his social theories. ${ }^{1}$ Moreover, this scholarship has concentrated on the influence of the theory of recapitulation as proposed by Ernst Haeckel (1866, 1873, 1874), despite the fact that Freud's version has a markedly different quality from the German zoologist. Freud's formulations on the matter were primarily focused on identifying how individual psychic development recapitulates social evolution, whereas Haeckel argued instead for a biological analogy between embryonic development and the evolution of the animal's remote ancestors. Freud's sociological version of recapitulation is aligned instead with authors such as Herder, Herbart, Comte, andforemost-Spencer.

Placing Freudian social thought in a social evolutionary tradition along the lines proposed here leads to a necessary revision of his work. Traditionally, Freud is placed in a pessimist tradition stemming from Schopenhauer (Bischler, 1939; Ellenberger, 1970; Gupta, 1975; Deigh, 1991; Schorske, 1991; Gardiner, 1997; Gardner, 1999; Gödde, 2010). By understanding it instead as embedded in doctrines merging evolution and progress, one reaches a different conclusion. His pessimism, following this analysis, is of a practical rather than metaphysical nature. According to this view, it is man's current constitution at this transitory stage of development that leads to the incongruities and conflicts between the individual and the group. Evolution would lead to increased adaptation between the individual and society that would generate, on the one hand, individuals more adapted to living under the constraints of civilized society, while, on the other, a society more capable of fulfilling the desires of the individual.

The comparative analysis further focuses on understanding the relation that the two authors established in regard to the problem of causes. This was a topic of central importance for the emerging social and psychological sciences in the nineteenth century. Since the positivist crusade against teleology, authors in these newly formed sciences could not choose but to address the problem of causes and its influence on questions 
about what type of science and methodology was most suited to approach phenomena in their disciplines. It is further argued that both Spencer and Freud complicated the matter to a great extent, by acquiring a perspective that is akin to the positivist one but that resorts to teleological notions-a position I here called natural teleology.

If, as Bury (1920/2006) argued in his classic The Idea of Progress, progress "is a theory which involves a synthesis of the past and a prophecy for the future" (p. 2), this is also true of the work of the two authors studied more closely in this paper. More than an account of the evolution of society, in his Synthetic Philosophy (1862-1893), Spencer developed a whole cosmology. This paper argues that, with psychoanalysis, Freud had a similar conception. ${ }^{2}$ In both authors, this involved speculation about the emergence of life, the descent of man, the evolution of civilization and, based on that genetic account, of a "prophecy for the future" of humanity. For Spencer and Freud, this prophecy also prescribed an ethical commitment for the individual, binding them morally into the future progress of civilization.

Historian Peter Bowler (1983) maintained that the relationship between social thought and biological theories has been marked by the absorption of biological theories into existing social debates as a form of providing further credibility and validity to pre-established ideologies. Because the relation between organisms to social formations is too complex to be precisely formulated causally, "in each case one aspect of the scientific theory was chosen to be stressed," so that "far from inspiring new attitudes, biological ideas were exploited as a means of justifying ideological positions that already existed" (p. 283). One such prominent example is the linear account of evolution, which states that species evolved in a linear path from lower to more complex and intelligent organisms. This idea, used extensively as a scientific proof of racial superiority in the nineteenth century, was in fact popular even before the idea of biological evolution first appeared (Burrow, 1966).

The final argument this essay makes is that the "prophecy for the future" formulated by both authors is deeply ideological. In both cases, but especially with Freud, not only was his culture taken as the model towards which all others should 
aspire, but his own personal dispositions and social role was taken as goals towards which all people must strive. Freud's perspective was not only ethnocentric but also self-centric. In his account of the progress of humanity, Freud not only made use of teleological notions of finality but also placed himself and his culture as the exemplars of that ideal.

\section{The Social Sciences and the Problem of Causes}

One common aspect to both the social sciences and psychology is their epistemological location at the edge of the two traditions classically described as Galilean and Aristotelian. The early years in both disciplines in the nineteenth century was marked by fierce methodological debates. The contrast is one between two distinct views on scientific explanation, and in particular about two notions of cause. This distinction is commonly defined as one between causal versus teleological notions. The first type is also called mechanistic, the latter finalistic. One aims to predict and explain (Erklären) phenomena, while the latter seeks to make facts teleologically or finalistically understandable (Verstehen). As it is classically understood, the development of modern science has been characterized by the progressive elimination of final causes from its modes of explanation. While von Wright (1971) argued that "the Aristotelian tradition today represents merely the fading survival of obsolete elements from which science is gradually becoming 'liberated'" (p. 2), Mayr (1992) made the case that biology only moved into the realm of the natural sciences through the elimination of teleological thinking $(1992,1998)$.

Teleology presupposes a tendency or purpose towards a given endpoint-i.e., the final cause. From the eighteenth and nineteenth centuries, such organizational tendencies were ascribed to essential natures or forces. A grown oak tree is, along those lines, the purpose or final cause of a seed; a seed contains within itself life forces that will transform it into a mature oak. In applying this explanatory framework to organisms, deviations from the purpose were read as marks of pathology. If organisms do not fulfil their purposes, this happens (following 
this perspective) due to some form of arrest in their natural development.

Such type of thinking led to several incongruities, foremost circularity. Molière in The Imaginary Invalid (1673/2004) famously mocked the character of the doctor in his play for subscribing to such circular arguments: "Why does Opium produce sleep?," he is asked. To which he answers: "Because there is in it a Virtus dormitive," i.e., a "dormitive power" (act III, sc. iii). Nietzsche (1886/2002), in turn, references Molière's play in order to ridicule Kant and the philosophers of Romanticism for similar reasoning:

"How are synthetic judgments a priori possible?" Kant asked himself, - and what was really his answer? By virtue of a faculty [Vermöge eines Vermögens], which is to say: enabled by an ability. Unfortunately, though, not in these few words, but rather so laboriously, reverentially, and with such an extravagance of German frills and profundity that people failed to hear the comical niaiserie allemande [German stupidity] in such an answer. [...] The honeymoon of German philosophy had arrived; all the young theologians of the Tubingen seminary ran off into the bushes-they were all looking for "faculties". [...] There had been dreamers: first and foremost - the old Kant. "By virtue of a faculty"-he had said, or at least meant. But is that really-an answer? An explanation? Or instead just a repetition of the question? So how does opium cause sleep? "By means of a faculty", namely, the virtus dormitiva-replies the doctor in Molière. (Nietzsche, 1886/2002, pp. 12-13)

Appealing to essential powers or forces can therefore be potentially misleading and tautological. If opium produces sleep, it can indeed be said of it to have "dormitive powers." However, when one asks the question in hand, one is in fact enquiring as to the mechanisms by which such an effect is produced. These are discovered by understanding the (efficient) causes, which entails breaking the phenomena into its elementary parts and explaining how these interact so as to produce the effect under study. 
Whereas such methodology worked with a large measure of success in the inorganic sciences, when applied to vital phenomena difficulties were encountered. How can it be said that the hand was not made for grasping, that a bird does not build a nest for laying eggs, or that a squirrel is not preparing for winter? In fact, similar criticism to that of Nietzsche's can be made of mechanical explanations. "Why are there sex differences?" one might ask. "Because of hormones," a mechanist would reply. Although true, it cannot be said that the answer has addressed the question. When one asks the question in hand, as philosopher Robert Brandon (1981) pointed out in his essay on teleological explanations, one is asking what are there sexual differences for, what is the purpose of it (p. 91).

As for the social sciences, the model established in the writings of Auguste Comte and John Stuart Mill in the 1830s and 40 s formed an ideal that was extended into the beginning of the twentieth century. The aim of both authors for the social sciences, in the Course de Philosophie Positive (1830) and the System of Logic (1843/1973) respectively, was to eliminate, as much as possible, the role of teleological explanations in the discipline and thus pave the way for it to become a science (Turner, 2003b, 2003a). Comte's most famous contribution, the "Law of the Three Stages," has as its inherent goal the elimination of final causes. According to the law, each science moves successfully through three stages of development. The "theological stage" is marked by an appeal to "fictitious entities"-gods, spirits and so on. It is followed by the "metaphysical stage," where explanations called for abstract forces-such as momentum and cause. In the final positivity stage, those ideas are eliminated, and purely predictive laws formed the whole of what was taken to be scientific in each domain.

The law did not speak of "forces" that assured the inevitability of this process. Comte, instead, theorized about the conditions for progress. The positive mind no longer asks why events unfold-it ceases to speculate on the hidden nature of things. Instead, it describes how phenomena arise and which course they take. Newton was taken as the model for this positivity. His description of motion and attraction no longer speculated on the essence of matter or movement, but simply aimed at de- 
scribing the laws governing these phenomena. Questions about the causes of gravitation no longer made sense, for asking such questions would invariably involve resorting to metaphysical or theological notions. Physics was, however, the only science to have, for the most part, arrived at the positivity stage. The emerging life sciences, on the other hand, had not yet moved that far. Social science was even further from liberation. Comte took this as his task.

His English counter-part, John Stuart Mill, discovered in Comte's Course "one of the most profound books ever written on the philosophy of the sciences" (Mill, YEAR, as cited in T. R. Wright, 1986, p. 41). This influence was particularly clear in his A System of Logic (Mill, 1843/1973), where Mill intended to oppose the influence exerted at the time by the "German, or a priori view of human knowledge," in particular that of Naturphilosophie, with "a text-book of the opposite doctrine-that which derives all knowledge from experience, and all moral and intellectual qualities principally form the direction given to the associations" (Mill, 1873/1969, p. 135). The book aimed at demonstrating how universal truths could be discovered solely via experience and association. Such an approach, however, required the assumption that nature is governed by universal laws. Underlying all laws of nature was a single principle, the "Law of Causation." This was nothing but:

The familiar truth that invariability of succession is found by observation to obtain the very fact in nature and some other fact which has preceded it, independently of all considerations respecting the ultimate mode of production of phenomena (Mill, 1843/1973, p. 327).

As there are no exceptions to the causal order, this also was also the case in humans-both in individuals (psychology) as in social formations (sociology).

Mill was, however, aware of the difficulty of the task. Events happening to both individuals and groups are at most times incapable of being determined causally. This is the case, not because they are not governed by causal laws, but due to their inherent complexity: 
[The] effects of the separate causes [...] are intermingled with, and disguised by, the homogenous and closely allied effect of other causes [...] some of which cancel one another, while others do not appear distinguishably, but merge in one sum [...] there is often an insurmountable difficulty in tracing by observation any fixed relation whatever. (1843/1973, p. 443)

The solution is thus to resort to statistics, studying many cases and thus producing approximate generalizations. As Turner (2003a) aptly noted:

[S] ocial science, for Mill, thus resembled the science of tides, which can never be reduced to a general theory. Although the main effects are understood, and predictions from these main effects are both possible and valuable, they are nevertheless subject to local causes of diverse kinds. (2003a, p. 64)

The method proposed by Comte and Mill became a divisive one within the discipline, but one that could not be simply neglected-and authors in the social sciences after them could be placed in a spectrum in relation to two extremes: the positivist causal view of the two authors at one end, and teleological understanding at the other. Along this spectrum, authors such as Marx and Hegel, whose emphasis in discovering single-factor laws of historical progress aim to make phenomena teleologically intelligible rather than predictable through knowledge of the efficient causes, would occupy the other end of the spectrum. Weber occupies a moderate teleological position, and Durkheim a moderate causal one. It is more difficult to classify Spencer. He assumed both views, so his perspective can be said to be ambiguous. While subscribing to the universality of natural law and explicitly rejecting teleology, he also believed that these laws revealed a purpose in nature. 


\section{Spencer: Organic analogy and the teleological law of progress}

Spencer's approach to determinism in his Synthetic Philosophy (1862-1893) looks at first similar to that of Comte and Mill. He sought to show that there are no exceptions to scientific explanations, in the form of natural laws, for all phenomena in the universe. Implicit in his project, however, was the goal of demonstrating that a thorough explanation of the laws guiding the universe-from the inorganic to the organic and including the mind and the social world-would reveal that these phenomena lead inexorably to progress. This reveals a debt of a different nature, in particular to philosophers of the Naturphilosophie: "Widely different as they are from my own, they are conceptions of the same class, and may very possibly have had some suggestive influences" (Spencer, 1904, p. 489). ${ }^{3}$ Thus, in similar approach to the positivist authors, Spencer believed in a law-based universe. Contrary to them, and from a perspective akin to teleology, the lawful universe was vested with value and meaning.

This second aspect might have been a direct influence from his father, George Spencer, who advocated a form of evolutionary deism that Thomas Mozley, a member of the Chapman Circle of which Herbert was also a participant, argued was the direct ancestor of the Synthetic Philosophy (1862-1893). Evolutionary deists saw God's providence as operating in the form of natural laws, with the purpose of engendering progress through natural development. Because these laws were believed to be initially set by God-or rather by the "GREAT FIRST CAUSE" (sic), as Erasmus Darwin, another evolutionary deist, preferred to call it -they should lead to maximum happiness (Taylor, 2007, pp. 38-42). Herbert Spencer explicitly rejected any appeal to teleological explanations, but one can easily identify in his description of nature's striving for perfection elements that would, in Comte's terms, belong to the metaphysical rather than the positivist stage. As Turner argued, "His discussions of the law have little to do with the incidence of conditions," as was the case with Comte, "and much to do with "general laws of force" (Turner, 2003a, p. 66). Spencer tended to see social 
stages as the fulfilment of a pre-existing disposition, which if not explicitly, is tacitly teleological.

Natural law was, for Spencer, the law of evolution. He saw it everywhere, from the development of the earth, to life, society, morals, commerce and language. In its most simple form the law stated that "All things are growing or decaying, accumulating matter or wearing away, integrating or disintegrating" (1897, p. 292). The fragment, however, conceals the arrow of nature: progress. This, for him-and borrowing the notion from German embryologist Karl Ernst von Baer (1792-1876)—consisted in the passage from the homogeneous to the heterogeneous, from the simple to the complex. Moreover, for Spencer, though regression and dissolution into simpler forms occurs under special circumstances, evolution, heterogeneity, complexity and progress are the rule rather than the exception in the grand scheme of things.

The reasoning behind it was rather simple and was explored in his essay on progress: if "every cause produces more than one effect," then "each kind of progress is from the homogeneous to the heterogeneous, and this is because each change is followed by several changes" (Spencer, 1857, p. 466; emphasis added). Progress and evolution thus refer to increasing heterogeneity. Spencer saw it in the formation of the universe (from singularity to plurality), of the solar system (an organized hierarchical system consisting of a star, planets and satellites), the surface of the earth (changing from a mass of matter of homogeneous consistency and temperature, to the heterogeneity of the environments found today), in the development of early forms of life which progress into increasingly heterogeneous flora and fauna, in man ("the most heterogeneous of animals," given the variety of races), societies (from aggregates of homogeneous individuals to heterogeneity in forms of authority), all the way to the subdivision in labour in industry, language and the arts.

The transition from the study of organic structures to the social sphere was accomplished via the organic analogy. In the second part of his Principles of Sociology (1885), Spencer outlined four points of analogy between organic and social aggregates, again aiming at demonstrating that both are phenomena regulated by the same law of increasing heterogeneity and indi- 
viduation. First, he said, (1) they both "exhibit augmentation in mass," i.e., they grow. The increase in size is supplemented by (2) the development of structure. The progressive differentiation of structures is accompanied by (3) the "progressive differentiation of function," i.e., heterogeneity. This differentiation gives rise to (4) the mutual dependency of parts. This is the 'fundamental trait' through which "a social organism and an individual organism are entirely alike." Because of the differentiation of functions, in both cases the aggregate exceeds its elemental units.

Progress, therefore, "is not an accident, not a thing within human control, but a beneficent necessity" (Spencer, 1857, p. 484). Civilization being part of nature, its modifications result from the law of evolution, and the

$[\mathrm{M}]$ odifications mankind have undergone, and are still undergoing, result from a law underlying the whole organic creation; and provided the human race continues, and the constitution of things remains the same, those modifications must end in completeness.

The law of evolution has therefore a normative, moral finality: "As surely as the tree becomes bulky when it stands alone, and slender if one of a group [...] so surely must things be called evil and immoral disappear; so surely must man become perfect" (Spencer, 1901, p. 156). For Spencer, therefore, not only are the laws of morality natural laws-nature itself is moral. It thus follows that the study of the nature of social formations has ethical consequences.

Concerning the ethical implications of the natural law, his message was one of radical laissez-faire. Real and long-standing progress was only brought about through evolution, which operates beyond the human control. Following this spirit of radical liberalism, the force that drove progress and social transformation was adaptation. Trying to mould evolution through mechanisms of social control (such as welfare) could only disturb the evolutionary process of adaptation between the individual and its environment. Individuals needed to become habituated to the demands of living in a social state, by 
developing the good habits required for new forms of social formation and eliminating those that ceased to be adaptive. As a believer in use-inheritance, Spencer saw it as the duty of each generation-understood as of each individual in that generation-to maximize adaptation in order to transmit the qualities needed for posterity, thus gradually building the path for perfection.

In a perfect state, the individual would instinctively respect the rights of others and refrain from any action that would cause pain. This ideal individual would behave with instinctive altruism, acting to give pleasure to others and deriving pleasure from the process. Spencer found the model of such dynamic in that of the mother feeding her child, an activity from which-in his view-both parties derive pleasure. In Social Statics (Spencer, 1851), he warned his readers that reaching perfect adaptation would take infinite time, but allowed for the state of equilibrium of the individual to the environment to become progressively approximate to the ideal. More than that, evolution in fact provided the ideal moral standard that individuals should strive to attain.

With the law of nature, Spencer was providing a guarantee for ideologies widely shared in Victorian society. He regarded Britain and America as the nations most closely representing the liberal ideal of his system. Although he personally despised colonialism and was a public denouncer of its atrocities (Francis, 2007, p. 283f.), his linear account of the development of societies, based on a deeper law of evolution that included all phenomena in the universe, was particularly useful for defending colonial practices in the expanding British empire. This helped make Spencer the most celebrated and revered philosopher of his time in Britain, the impact of his ideas extending widely to authors in Europe and America (Jones and Peel, 2004; Francis and Taylor, 2014).

\section{Freud: From the Organic to the Libidinal Analogy}

The linear understanding of the evolutionary process was central to most social evolutionist theory in the nineteenth century. As Bowler (1983) argued: 
[D] espite Darwin's emphasis that development is a branching rather than a linear process, the vast majority of his followers continued to believe that evolution of man consisted of a single line of ascent from the apes. The idea that the "lower" races might represent intermediate stages in the chain of being linking the apes to man had been developed in the eighteenth century and was still popular in the early nineteenth century. (1983, p. 302).

This was true of the most eminent proponent of social evolutionism, Herbert Spencer, but also of Sigmund Freud.

Social evolution for Freud takes a linear form, following a pre-existing disposition. Throughout his writings on the genesis and development of groups and cultures, from Totem and Taboo (1913) to his last book, Moses and Monotheism (1939), he described the development from the state of nature to civilization as occurring by a progression of stages shared by all cultures. In brief, his account of the descent of men begins with (1) the human hordes, with men in a Hobbesian state of nature. In this mythical period, the individual lived in a state of complete narcissistic omnipotence, solely regulated by the pleasure principle, i.e., with no restriction of instincts, but at the same time in complete dependence on others, and with feelings of total helplessness against the oppressive forces of nature (Freud, 1930, p. 123) - which drove these proto-people, who would otherwise live in solitude, to gather in groups. The "tyrannical father," i.e., the strongest and most powerful male leader of the horde, had the monopoly of women in the group, but at some point in pre-historic time he was killed and devoured by his oppressed children, thus generating guilt and the development of the first social contract (1913 $\overline{\mathbf{z}}_{\mathbf{2}}$ 1939, pp. 82-83). This act inaugurated the (2) totemic societies (in fact, it could be said that this act inaugurates culture itself), marked by the establishment of animal gods representing the dead father and by women occupying the positions of power.

The next step (3) in the development of civilization was the humanization of the forces of nature in pantheism (Freud, $1913_{2} 1939$, p. 83). With this stage, a deeper mastering of reality was gained. Since the forces of nature now behaved in a way 
similar to ours, we were able to comprehend it. Nature ceased to be so terribly frightening and became more familiar (Freud, 1927, pp. 14-15). This stage is followed by the appearance of (4) monotheism. The polytheistic gods progressively withdrew from nature, and "morality becomes their true domain" (1927, p. 18). Now the gods served two purposes: they defended men 'against the dangers of nature and Fate, and against the injuries that threaten him from human society itself-. At last, all gods were condensed in one, and monotheism was instituted (1927, p. 19). The primal Father, who was always present in the civilization's unconscious, was returned. There is one last step in this process, usually neglected by Freudian scholars, (5) the establishment of a rational society, based on the scientific Weltanschauung. There is no further stage, for "there is no appeal to a court above that of reason" (1927, p. 26). Reason is thus the final aim of civilization. Freud contended that the transition to the last stage had just started, and the process is expected to be long, but "in this process there is no stopping; the greater the number of men to whom the treasures of knowledge become accessible, the more widespread is the falling-away from religious belief" (1927, p. 38).

The parallel to Comte's stages is fairly evident. By taking into account that Comte broke down the theological stage into three sub-stages-animism, polytheism and monotheism-the similarity is even more striking. Thus, there are almost direct parallels between Comte's animism and Freud's totemic stages, between the first's polytheism and the latter's pantheism, and so on, all the way down to the positivity stage-the main dissimilarities being that Comte did not provide for an initial state of nature in the same way as Freud, and that Freud merged the monotheistic and metaphysical stages into one. This analogy has been curiously overlooked by most of the literature. Philip Rieff (1959) is one of the few authors to have stressed the impact of Comte's positivism in Freud's social theories, in particular where he argued-against Sulloway and others who claimed that the impact of evolutionism in Freud was primarily effected via Ernst Haeckel's version of recapitulation-that 
Freud did not much employ this [i.e., Haeckel's] biological version of analogy between individual and racial development $[\ldots]$. A more nearly sociological version, familiar through the variety of uses to which it was put by Herder, Herbart, Comte, and Spencer, is the one more often employed. (Rieff, 1959, p. 188)

Nevertheless, he said nothing there about the specific set and order of stages, which is similar only in the cases of Comte and Freud. The only other author who has touched on the analogies between the schemes as presented here seems to have been Jean Laplanche. In his Court traité de l'inconscient, after discussing Comte's stages, Laplanche argued that "Freud in turn endorses a succession [of stages of civilization] which is not very far from [Comte's], despite somewhat different terms: animistic, religious, scientific worldview" (Laplanche, 1993, p. 94).

Despite the similarities between the two systems, one striking difference distinguishes them. Whereas Comte theorized the conditions for progress, Freud instead affirmed its inevitability. While for the former progress is not necessary and certain, but a consequence of particular states of affairs being fulfilled in determinate groups, Freud instead understood progress as an inexorable process in any civilization, driven by the force of evolution. By understanding progress as inevitable and as a consequence of the law of evolution, Freud is aligned with Spencer's position that I have here called natural teleology. ${ }^{4}$

In that sense, Freud followed his contemporaries by equating evolution and progress. The novelty introduced by social evolutionists was to apply this moralizing view of the evolutionary process to the understanding of groups. From the moral character-that societies are more or less developed-followed a normative one. The more developed societies were taken as models to which the others should strive. For Freud, Western culture was the point of reference from which "primitive societies," not usually distinguished from one another, were measured. Throughout his work, "savages" were often compared to children (1913, p. 62; 1920, p. 117), while intellectualized Westerners of the upper classes were treated as adults. The Western civilization, being more developed than the others, 
had merely shown the path that all other cultures would take independently of the western civilization's existence itself. Evolution is a single road, and Western civilization was ahead only because it travelled along this path earlier than others.

In Freud's social evolutionist framework, not only were there more and less developed societies, but there were also more and less developed social classes. The "masses," said Freud, "are lazy and unintelligent; they have no love for instinctual renunciation" (1927, p. 7). James Strachey, Freud's translator, who normally translated the German Masse as "Groups," in this instance kept the denigrating tone of the original. Individuals inside a determinate social class were also deemed more or less developed. The figure of the intellectual, taken by Freud as the ideal example of a "minority" that achieved "higher cultural aims" (1908, p. 193) through sublimation, achieved the highest standards in civilization, and was therefore taken as the role model to which all other individuals should ideally adapt in order to build a more fulfilling society. Thus, Freud not only took his culture as the model for all others, but he also ascribed to his social role and personal predisposition the goals towards which all people within his culture should aspire.

Each stage marked a new form of mastering of reality, a new mode of defense against nature, for this is the main task of civilization (1927, p. 15). The stages have not been arbitrarily chosen - the civilizatory stages, says Freud, mirror the psychosexual stages of libidinal development. Whereas Spencer used an organic analogy between the individual and the social, Freud made use instead of what could be called a libidinal analogy. By comparing the psychological development of the individual-from autoeroticism to the post-oedipal adult- to the evolution of civilization from state of nature to a rational society, it becomes possible for him to sketchily map the stages of development in individual and group psychology. One prominent example is found where he argued that "[monotheistic] religion would thus be the universal obsessional neurosis of humanity; like the obsessional neurosis of children, it arose out of the Oedipus complex, out of the relation to the father" (1927, p. 43). Freud was not referring to pathological obsessional neurosis in adults, but to a hypothetical neurotic phase in normal development, which is spontaneously overcome in 
the course of development. That is, monotheism indicates a particular stage in the development of civilization which, in the individual, takes place at about the oedipal period.

This was also the kernel of Freud's criticism of religion. In the same way that this infantile neurosis must be overcome at the individual level, it must also be surpassed in the social sphere. Humanity must reach maturity, and maturity entails replacing neurotic phantasies with reality-tested secondary-process:

Those historical residues have helped us to view religious teachings, as it were, as neurotic relics, and we may now argue that the time has probably come, as it does in an analytic treatment, for replacing the effects of repression by the results of the rational operation of the intellect. (Freud, 1927, p. 44)

Freud mainly pursued this line of thinking in his writings of the 1910s's whilst in active correspondence with the Hungarian psychoanalyst Sandor Ferenczi-Totem and Taboo from 1913 being an exemplary publication of that period. However, nowhere has Freud taken this speculative enterprise so far as in his "phylogenetic phantasy," i.e., his unfinished and posthumously published metapsychological paper on the transference neuroses (Freud, 1915/1987). There, and in particular in its second part, Freud attempted to trace direct correlations between three levels of evolution and regression: that of society according to the stages, that of libidinal development in the individual, and of regression in different types of psychopathology. If the evolution of the individual recapitulates the evolution of civilization, and psychopathology represents a psychic regression to some stage of development in the individual, Freud hypothesizes there that "it is legitimate to assume that the neuroses must also bear witness to the history of the mental development of mankind" (1915/1987, p. 11). He goes as far as to hypothesize that the disposition to hysteria and compulsion must present regressions to a stage of development that occurred during the Ice Age (p. 13).

Freud never managed to complete this analogical mapping. He would return to this project from time to time, but with less emphasis on completing the task as he became increasingly 
more aware that this laid beyond his means. In Civilization and its Discontents, he seemed to pass on the torch to one of his readers, where he says that "it would be a tempting task for anyone who has a knowledge of human civilizations to follow out this analogy in detail" (Freud, 1930, p. 140).

\section{Progress and the Ethics of Psychoanalysis}

This process of social evolution, according to Freud, happens at a cost: "The price we pay for our advance in civilization is a loss of happiness through the heightening of the sense of guilt" (Freud, 1930, p. 135). For every new civilizatory stage, a toll must be paid in the form of instinctual repression. All those accumulated repressions, the base of our civilization, are still present and active in every individual, who resents them: "We have found to our surprise that these privations are still operative and still form the kernel of hostility to civilization" (Freud, 1927, p. 10). The individual is therefore ambivalent in relation to civilization. $\mathrm{He}$ is at the same time its enemy and guardian, because although the end of civilization might bring him unrestrained pleasure, it would also signify the return of the tyrannical father:

[A]nd so in reality only one person could be made unrestrictedly happy by such a removal of the restrictions of civilization, and he would be a tyrant, a dictator, who had seized all the means to power [...] how ungrateful, how short-sighted after all, to strive for the abolition of civilization! (1927, p. 15)=

Because Freud placed the conflict between the individual and society at the core of the human condition, the scholarly work on Freud has classically placed his social theories in a pessimistic tradition stemming from Schopenhauer. This reading, however, overlooks the evolutionary aspect of his work highlighted here. Unlike Schopenhauer, Freud's pessimism does not translate into nihilism. Following from his linear understanding of social evolution, it is expected that at the last stage of evolution 
(scientific Weltanschauung), in a society where individuals are regulated solely by the reality principle, conflict between the individual and the social environment would cease or at least greatly diminish.

Not even the advent of the death drive in 1920 seems to have changed that drastically his belief in progress, as seven years after the publication of Beyond the Pleasure Principle (1920) — where the concept was first consistently articulated-he still proclaimed in Future of an Illusion (1927) that "the primacy of the intellect lies, it is true, in a distant, distant future, but probably not in an infinitely distant one" (p. 51), an argument he would again repeat in similar form in the New Introductory Lectures (1933a, p. 171). In-between the "optimism" of these two works, however, stands the grimmer picture depicted in Civilization and its Discontents (1930). This has puzzled scholars, who have at times argued that Freud held two competing and incongruous social theories: the first, a classic utilitarian view held until the late 1920s; the latter, the pessimism from Civilization and its Discontents (1930) onwards, where the concept of the death drive is properly articulated in his social theory (Deigh, 1991).

This reading, I believe, falls apart upon closer inspection. Firstly because, as mentioned, the supposed "shift" has not occurred after Beyond the Pleasure Principle (1920) as one might expect. Future of an Illusion (1927) was written seven years after that essay, and at a time when Freud was most preoccupied with thinking the repercussions of the death drive. A counterargument could be made that Freud did not become fully aware of the social implications of the death drive until 1930. However, the view portrayed in the New Introductory Lectures, from 1933, offers a decisive rebuttal to that. Finally, by following this analysis, one would be forced to argue that Civilization stands at a unique position is his work.

Another interpretation is possible and would avoid this awkward schism in his work. The difference between Future and Civilization, along those lines, is rather one of historical perspective. In Future and New Lectures, where Freud is primarily concerned with offering a treatment of the natural history of our species, his stance takes a more optimistic tone since the 
timeframe of his analysis stretches infinitely into the future. In Civilization, on the other hand, he is directly addressing current events leading to another world war. In not having the benefit of infinite time, his analysis takes a more cautionary tone. When analysing human evolution through the point of view of natural history, it becomes possible for him to envisage a future where civilization would produce little or no harm to the individual. The problem laid for Freud with our present constitution, i.e., the fact we are at the same time rational and irrational, social and narcissistic. Evolution would bring more adapted beings in the future, together with other forms of social organisation that would be more fulfilling for the individuals living in them. In the short-term, however, our current constitution might bring momentary regressions in this inexorable process.

As Joshua Dienstag (2006) argued in his book tracing the philosophical tradition of pessimism, Freud's pessimism is of a practical and not metaphysical nature. There, he noted that

[... I $] \mathrm{n}$ repeatedly identifying the pleasure principle with infancy and animality, Freud means to encourage our efforts to replace it more fully with the reality principle. To accept the limitations of our time-bound conditions is for Freud the mark of emotional and intellectual maturity; to resist them is childish. Where Schopenhauer's philosophy [...] teaches us to leave this world behind to the greatest extent possible, Freud's psychotherapy attempts to give us the tools with which to engage it. (2006, p. 101)

For Freud, our individual actions are effective and do have the power to produce a positive change in the world, or the practice of psychoanalysis itself would be vain. It is interesting to note that, as was the case with Spencer, Freud placed the burden of social progress onto the individual rather than on mechanisms of social change. The latter should follow as a consequence of the former, not the other way around. Richard Sterba (1978) showed this in greater clarity in a paper where he described discussions that took place in the early Wednesday Group meetings at Freud's house in Vienna, of which he was 
a participant. In one of the meetings, Wilhem Reich gave a passionate presentation of how some recent social experiments taking place in post-revolutionary Russia would-according to him-free humankind of neurotic suffering. Freud was extremely sceptical of this argument and, according to Sterba, his criticism was one of the reasons that led Reich to break with the group (Sterba, 1978).

Social change, for Freud, could therefore be achieved only via the development of the individual, by helping them overcome their neuroses that are characteristic of this transitional (although potentially endless) stage between monotheism and the establishment of a scientific Weltanschauung. One should also not overlook the fact that Freud was a strong believer in Lamarckian use-inheritance (Sulloway, 1979; Ritvo, 1990; Young, 2006). Therefore, each individual achieving greater maturity meant a further step in the process of development of society as a whole. Psychoanalysis, in this sense, could be seen as constituting an ethical project, aimed at the progress of society, one individual at a time. Freud articulated this clearly at least once:

I should therefore like to let you go with an assurance that in treating your patients psycho-analytically you are doing your duty in more senses than one. You are not merely working in the service of science, by making use of the one and only opportunity for discovering the secrets of the neuroses; you are not only giving your patients the most efficacious remedy for their sufferings that is available to-day; you are contributing your share to the enlightenment of the community from which we expect to achieve the most radical prophylaxis against neurotic disorders along the indirect path of social authority. (Freud, 1910, p. 151)

With psychoanalysis, Freud provided his readers with both a framework to understand themselves and their personal development, as well as with a technique with which to achieve the psychic maturity required for social progress. This technique consisted not only of the process of analysis "on the couch" itself but, above all, of the tools for self-analysis presented in 
clinical case materials and especially in the Interpretation of Dreams (1899). With his dream book and case studies, Freud presented his readers with a manual on how to conduct a self-analysis (Forrester, 2006, 2013), thus developing themselves, and society with them. "Ethics," as Freud pointed out in Civilization, "is thus to be regarded as a therapeutic attempt—as an endeavour to achieve, by means of a command of the super-ego, something which has so far not been achieved by means of any other cultural activities" (1930, p. 142). Ethics is therefore a therapeutic action, and therapy is an ethical activity.

\section{Conclusion}

As Taylor summarized in his recent book on Spencer:

$[\mathrm{T}]$ he synthetic philosophy held two very different worldviews in an uneasy balance. One of these was positivism, the notion that the universe could only be explained by natural laws, and that there was a radical separation of fact and value. [...] At the same time, however, Spencer also made use of a normative concept of nature (he almost always spelled it with a capital letter) as not merely a physical order, but also a moral one. As such, his philosophy was implicitly, if not explicitly, founded on a rejection of the fact-value distinction that was central to the scientific positivist account of the universe. (Faylor, 2007, pp. 7-8)

This was the case, it was argued, because of his teleological understanding of the natural law. It was further argued that Freud had a similar conception. Both authors can be seen as subscribing to a position I here called natural teleology. Where Spencer based his organic analogy on elements of the sciences of his time, in order to validate the ideology embedded in his social theories, Freud relied instead in his metapsychology of drives and libidinal energy to provide a libidinal analogy.

Drives are abstract elemental parts of human motivation, and therefore concepts belonging in principle to what the 
philosopher Wilfrid Sellars called the scientific image of man (Sellars, 1963). In that image, man is seen as an object, composed of elementary parts (neurons, cells, and so on) that interact causally so as to construct who we are. This contrasts with the manifest image, where explanations are based on personal intentions, beliefs and desires. In the manifest image, teleology and intentionality play a major role in explaining action. The best explanation for the action of a man drinking water is, along these lines, not mechanisms regulating homeostasis, but simply thirst-that is, his wish or desire for water.

As elementary parts of personhood, drives should be ascribed to the scientific image. Freud however let teleology creep into metapsychology. In Instincts and their Vicissitudes, he gave us his classic description of drives, along with their four main features. Particular focus is given there to their aim: satisfaction (Freud, 1915, p. 121). If drives have aims, they exhibit teleology. Drives behaving teleologically, it follows that a social theory from an analogy with them would also exhibit that feature. This leads Freud to appeal to explanations of social phenomena that are very much aligned with those defended by the doctor in Molière. "Why war?," Einstein asked Freud in their famous letter exchange (Freud, 1933b). "Because of the death drive"that is, due to a force of aggression-is essentially what Freud answered. One is thus entitled to repeat Nietzsche's rebuttal: "But is that really-an answer? An explanation? Or instead just a repetition of the question?"

\section{Notes}

1. See also Ritvo (1990) and Young (2006).

2. It is important to note, however, that I am not here making specific claims regarding the filiation of ideas. It is hard to evaluate with any level of precision how familiar Freud was with Spencer's Synthetic Philosophy (1862-1893). None of his works are available in Freud's personal library in London (Trosman \& Simmons 1973) but it is possible that these were left behind during his emigration from Vienna, as he did quote Spencer in three of his writings (Freud, 1900, p. $1_{\overline{2}} 1905$, pp. 145-6-1913, p. 74). Freud's contact with Spencer might have been indirectly transmitted, via his reading of the English neurologist John Hughlings Jackson, who applied Spencerian ideas of evolution to the understanding of brain hierarchies (Hughlings Jackson, 1884; York and Steinberg, 2002; Franz and Gillett, 2011; Niro Nascimento, 2017).

3. Although Spencer seemed to be at least familiar with the works of Hegel and Schelling, Naturphilosophie might have impacted him more directly via the writings of Lorenz Oken, a follower of Schelling who, in his "Physiophilosophie" from 1810, 
interpreted nature as self-developing towards increasing levels of organisation and, in a way very much like Spencer, made extensive use of analogy between findings of different sciences-from astronomy to psychology-in order to demonstrate his theories (Taylor, 2007, p. 45).

4. Natural teleology bears some resemblance to what Timothy Lenoir called steleomechanism, - and may be considered an offshoot of it, or least greatly impacted by it. :The teleomechanism research programme, 2 according to Lenoir, consisted of a series of physiologists in mid-19th century Germany who argued that the life sciences must ultimately rest on an explanatory framework uniting the principles of both teleology and mechanism (Lenoir, 1981, 1982). The main similarities between teleomechanism and natural teleology are therefore the confluence of mechanism and teleology, but also that both groups had a concept of force driving matter according to aims. However, while the driving force in natural teleology is evolution, in teleomechanism it was some concept of vital force (Lebenskraft). Moreover, the notion of teleomechanism is used to name a defined set of scientists working in the Germany, while the notion of natural teleology is looser than that and is primarily related to filiation to this set of ideas. It is also worth noting that Karl Ernst Baer, the main author studied by Lenoir as part of teleomechanism (Lenoir, 1988), was the prime influence behind Spencer's (and Haeckel's) notion that evolution moves from homogeneity to heterogeneity-which indicates an influence.

5. The execution of this ethical project can also be observed in the formation of the psychoanalytic policlinics, in which, as Elizabeth Danto demonstrated in her Freud's Free Clinics, Freud and many of the early psychoanalysts were heavily involved in the period after the First World War (Danto, 2005). Their fervour for treating the poor can be understood not only as a means to provide more humane treatment to those without access to private therapy, but also as a missionary work of converting more people into psychoanalysis-and thus into social development.

\section{References}

Bischler, W. (1939). Schopenhauer and Freud: a comparison. The Psychoanalytic Quarterly, 8, 88-97.

Bowler, P. J. (1983). Evolution: The History of an Idea. Revised Ed. Berkeley: University of California Press.

Brandon, R. N. (1981). Biological teleology: Questions and explanations. Studies in History and Philosophy of Science Part A, 12(2), 91-105. dc tp://dx.doi. org/10.1016/0039-3681(81)90015-7.

Burrow, J. W. (1966). Evolution and Society: A Study in Victorian Social Theory. Cambridge: Cambridge University Press.

Bury, J. B. (2006). The Idea of Progress: And Inquiry into its Origin and Growth. Middlesex: The Echo Library.

Danto, E. A. (2005). Freud's free clinics-: psychoanalysis social justice, 1918-1938. New York: Columbia University Press.

Deigh, J. (1991). Freud's later theory of civilization. In Neu, J. (ed.), The Cambridge Companion to Freud (pp. 287-308). Cambridge: Cambridge University Press. doi: 10.1017/CCOL0521374243.013.

Ellenberger, H. F. (1970). The discovery of the unconscious; the history and evolution of dynamic psychiatry. New York: Basic Books.

Forrester, J. (2006). Remembering and forgetting Freud in early twentieth-century dreams. Science in context, 19(1), 65-85. doi: 10.1017/S0269889705000761.

Forrester, J. (2013). Dream Readers. In Marcus, L. (ed.), Sigmund Freuds The Interpretation of Dreams (pp.83-122). Texts in C. Manchester: Manchester University Press.

Francis, M. (2007). Herbert Spencer and the invention of modern life. Stocksfield: Acumen. Francis, M. and Taylor, M. W. (Eds.). (2014). Herbert Spencer: Legacies. Oxon: Routledge. 
Franz, E. and Gillett, G. (2011). John Hughlings Jackson's evolutionary neurology: a unifying framework for cognitive neuroscience. Brain : a journal of neurology, 134(10), 3114-3120.

Freud, S. (1900 [1899]). The interpretation of dreams. Standard Edition (Volume 4, pp. ix-627). London: Hogarth Press.

Freud, S. (1905). Jokes and their Relation to the Unconscious. Standard Edition (Vol. 8, pp. 1-247).

Freud, S. (1908). Civilized' Sexual Morality and Modern Nervous Illness. Standard Edition (Vol. 9, pp. 177-204). London: Hogarth Press.

Freud, S. (1910 [1909]). Five lectures on psycho-analysis. Standard Edition (Vol. 11, pp. 1-5). London: Hogarth Press.

Freud, S. (1913). Totem and Taboo. Standard Edition (Vol. 13, pp. 1-162). London: Hogarth Press.

Freud, S. (1915). Instincts and their Vicissitudes. Standard Edition (Vol. 14, pp. 109-140). London: Hogarth Press.

Freud, S. (1920-1922 [1921]). Group Psychology and the Analysis of the Ego. Standard Edition (Vol. 18, pp. 65-144). London: Hogarth Press.

Freud, S. (1927). The Future of an Illusion. Standard Edition (Vol. 21, pp. 1-56). London: Hogarth Press.

Freud, S. (1930 [1929]). Civilization and its Discontents. Standard Edition (Vol. 21, pp. 57-146). London: Hogarth Press.

Freud, S. (1933a [1936]). New Introductory Lectures On Psycho-Analysis. Standard Edition (Vol. 22, pp. 1-182). London: Hogarth Press.

Freud, S. (1933b). Why War? Standard Edition (Vol. 22, pp. 195-216). London: Hogarth Press.

Freud, S. (1939). Moses and Monotheism. Standard Edition (Vol. 23, pp. 1-138). London: Hogarth Press.

Freud, S. (1987). A Phylogenetic Phantasy: An Overview of the Transference Neuroses. Edited by I. Gubrichs-Simitis, A. Hoffer, and P. T. Hoffer. Cambridge, MA: Harvard University Press.

Gardiner, P. L. (1997). Schopenhauer. Bristol: Thoemmes Press.

Gardner, S. (1999). Schopenhauer, Will, and the Unconscious. In Janaway, C. (ed.), The Cambridge Companion to Schopenhauer (375-421).

cal abridge: Cambridge University Press.

lde, G. (2010). Freud and nineteenth-century philosophical sources on the unconscious. In Nicholls, A. and Liebscher, M. (eds.), Thinking the Unconscious (261-286). Cambridge: Cambridge University Press.

Gupta, R. K. (1975). Freud and Schopenhauer. Journal of the History of Ideas, 36(4), 721.

Haeckel, E. (1866). Generelle Morphologie Der Organismen. Allgemeine Grundzüge Der Organischen Formen-Wissenschaft, Mechanisch begründet Durch Die Von C. Darwin Reformirte Descendenz-Theorie, Etc. Berlin: Georg Reimer.

Haeckel, E. (1873). Natürliche Schöpfungsgeschichte. Berlin: Georg Reimer.

Haeckel, E. (1874). Anthropogenie oder Entwickelungsgeschichte des Menschen: Keimes- und Stammes-Geschichte. Leipzig: Wilhelm Engelmann.

Hughlings Jackson, J. (1884). The Croonian Letures on the Evolution and Dissolution of the Nervous System: Lecture II. British Medical Journal, 7, 660-663.

Jones, G. and Peel, R. (2004). Herbert Spencer: the intellectual legacy. London: Galton Institute.

Laplanche, J. (1993). Court traité de l'inconscient. Nouvelle Revue de Psychanalyse, 48, 69-97.

Lenoir, T. (1981). Teleology without regrets. The transformation of physiology in Germany: 1790-1847. Studies in History and Philosophy of Science Part A, 12(4), 293-354.

Lenoir, T. (1982). The Strategy of Life: Teleology and Mechanics in Nineteenth-Century German Biology. Chicago: The University of Chicago Press.

Lenoir, T. (1988). Kant, Von Baer, and Causal-Historical Thinking in Biology. Poetics Today Interpretation in Context in Science and Culture, 9(1), 103-115.

Mayr, E. (1992). The Idea of Teleology. Journal of the History of Ideas, 53(1), 117-135. 
Mayr, E. (1998). The Multiple Meanings of "Teleological." History and Philosophy of the Life Sciences, 20(1), 35-40.

Mill, J. S. (1969). Autobiography. Edited by J. Sttillinger. Boston: Houghton Miffin.

Mill, J. S. (1843/1973). A System of Logic: ratiocinative and inductive, being a connected view of the principles of evidence, and the methods of scientific investigation. Edited by $\mathrm{J}$. M. Robson. London: Routledge.

Molière. (2004). The Imaginary Invalid. Edited by H. van Laun. London: Dover Publications.

Musil, R. (1953). The Man Without Qualities. London: Minerva.

Nietzsche, F. (2002). Beyond Good and Evil. Cambridge. Edited by R.-P. Horstmann and J. Norman. Cambridge: Cambridge University Press.

Niro Nascimento, L. (2017). Evolution in the Brain, Evolution in the Mind: The Hierarchical Brain and the Interface between Psychoanalysis and

N eur science. Psychoanalysis and History, 19(3), 349-377.

N-, R. A. (1994). History of the Idea of Progress. London: Transaction.

Rieff, P. (1959). Freud: The Mind of the Moralist. New York: The Viking Press.

Ritvo, L. B. (1990). Darwin's influence on Freud: a tale of two sciences. New Haven: Yale University Press.

Schorske, C. (1991). The Psychoarcheology of Civilizations. In Neu, J. (ed.), The Cambridge Companion to Freud (pp. 8-24). Cambridge: Cambridge University Press.

Sellars, W. (1963). Empiricism and the Philosophy of Mind. Routledge. London.

Spencer, H. (1851). Social Statics: or, The Conditions essential to Happiness specified, and the First of them Developed. London: John Chapman.

Spencer, H. (1857). Progress: Its Law and Causes. The Westminster Review, 67, 445-485.

Spencer, H. (1885). Principles of Sociology. Vol 2. London: Williams and Norgate.

Spencer, H. (1897). First Principles. New York: Appleton.

Spencer, H. (1901). Essays Scientific, Political and Speculative. Vol. 2. New York: Appleton.

Spencer, H. (1904). An Autiobiography. Vol. 2. New York: Appleton.

Sulloway, F. J. (1979). Freud, Biologist of the Mind: Beyond the Psychoanalytic Legend. bridge, MA: Harvard University Press.

Taylor, M. W. (2007). The Philosophy of Herbert Spencer. London: Continuum.

Trosman, H. and Simmons, R. D. (1973). The Freud library. Journal of the American Psychoanalytic Association, 21(3), 646-87. http://www.ncbi.nlm.nih.gov/ pubmed/4583570.

Turner, S. (2003a). Cause, Teleology, and Method. In Porter, T. M. and Ross, D. (eds.), The Cambridge History of Science Volume 7: The Modern Social Sciences (pp. 57-70). Cambridge University Press.

Turner, S. (2003b). Cause, the Persistence of Teleology, and the Origins of the losophy of Social Science. In Turner, S. and Roth, P. A. (eds.), The Blackwell G.... to the Philosophy of the Social Sciences (pp. 21-41). Oxford: Blackwell Publishing.

von Wright, G. H. (1971). Explanation and Understanding. Cornell University Press.

Wright, T. R. (1986). The Religion of Humanity: the Impact of Comtean Positivism on Victorian Britain. Cambridge: Cambridge University Press.

York, G. K. and Steinberg, D. A. (2002). The philosophy of Hughlings Jackson. Journal of the Royal Society of Medicine, 95(6), 314-8.

Young, A. (2006). Remembering the Evolutionary Freud. Science in Context, 1(19), $175-189$. 